IIUC STUDIES

ISSN 1813-7733

Vol.- 7, December 2010

(Published in December 2011) (p 25-36)

\title{
The Role of Context in Teaching English to the Speakers of Other Languages (TESOL)
}

\author{
Md. Humayun Kabir*
}

\begin{abstract}
In this article, we have tried to develop a clear concept of approach i.e.-language theory and learning theory and also presented the idea of method i.e. - a way of teaching a language which is based on systematic principles and procedures. Subsequently, we have tried to clarify the notion of context. In the discussion, I have attempted to explain why the consideration of contextual factors is vitally important in applying an approach or method by a language teacher while she/he teaches. I have also examined and given references to the context of my teaching experience in Bangladesh which are relevant to the thesis of this article.
\end{abstract}

\section{Introduction}

Approaches and methods in teaching English as a foreign language can be seen as a historical progression of revolutions and evolutions, and also as a growing range of teaching options. In trying to apply approaches and methods, teachers sometimes ignore the context in which teaching and learning occur, but it is important to pay attention to the context. In this article, firstly, I will discuss the terms - approach and method to establish a link between approach, method and context. After doing this, we will explore the notion of context and its components like cultural, political, institutional and classroom context. We will also try to show the importance of the evaluation of these

${ }^{*}$ Assistant Professor, Dept. of English Language \& Literature, IIUC. 
contexts while approaches or methods are applied to language teaching, with references to the teaching context in Bangladesh.

\section{Approach}

An approach is a level of belief. At this level, assumptions and beliefs about language and language learning are specified. Hence, theoretical principles are described in an approach. We will find that both the language theory and learning theory are the subject matters of an approach. The language theory embodies a model of language competence and an account of the fundamental characteristics of linguistic organization and language use. On the other hand, the learning theory covers 'an account of the central process of learning and an account of the conditions believed to promote successful language learning' (Richards and Rodgers, 2001, p.24). No approach specifies any procedure of teaching a language. It is a design which links an approach with a procedure. A particular view of language and theory of learning will help a teacher to formulate her/his own teaching procedure. Anthony (1963, pp.63-67) holds 'an approach is a set of correlative assumptions dealing with the nature of language teaching and learning. An approach is axiomatic. It describes the nature of the subject matter to be taught', cited in Richards and Rodgers (2001, p.19). Again, we find almost a similar view in Richards and Rodgers (2001, p.20) where they maintain 'approach refers to theories about the nature of language and language learning that serve as the source of practices and principles in language teaching.' But, no approach leads to 'a specific set of prescriptions and techniques to be used in teaching a language', (Richards and Rodgers, 2001, p.245) .An approach to language teaching and learning represents an outline notion of the way in which theses should go on, 'a seedbed from which a method springs, but is not yet a strategy specifying details of classroom practice', (Johnson and Johnson, 1998, p.11). There must be a logical fit between an approach and a method. Within one approach, there can be many methods. Approaches can be revised and updated if any context requires. So, it is the context which should have been the first consideration of the language teacher during the application of an approach. Now we will see how a language teaching method is closely associated with the context where a language is taught.

\section{Method}

A method is a way of teaching a language by following systematic principles and procedures. A method includes the actual activities the learner and the teacher are engaged in while teaching and learning a language. Davies and Pearse (2000, p.208) opine that a method is the 
'way of teaching based on ideas about language, learning, and teaching, with specific indications about activities and techniques to be used'. A theory of language is put into practice in a method. A method is more abstract than teaching activities. Knowledge of methods is part of the knowledge base of teaching. It helps to widen a teacher's repertoire of techniques. Anthony (1963, pp.63-67) defines, 'method' is an overall plan for the orderly presentation of language material, no part of which contradicts, and all of which is based upon, the selected approach. An approach is axiomatic, a method is procedural', cited in Richards and Rodgers (2001, p.19). Methods 'describe a certain ideal, based on certain beliefs. They deal with what, how and why. They say little or nothing about who/ whom, when, and where,' (Larsen-Freeman, 2000, pp.181-182).

Social relations, forms of thinking and strategies of learning are the embodiments of methods. From the above discussion we are convinced that the proper evaluation of context is a must when a method is applied. Language teachers should assess the context of a particular country or an area while they apply a method to teaching. The following discussion will clarify the idea of context.

\section{Context}

By the notion 'context', we will refer to the broader social situation. In language teaching, the wider view of context includes both learners and settings where teaching and learning occur. The Oxford Advanced Learner's Dictionary (1996) defines 'context' (2) as 'circumstances in which something happens or in which something is to be considered.' Longman Dictionary of Contemporary English (1995) explores it as 'the situation events or information that are related to something, and that help you to understand it better'. We also know that Language teaching and learning take place in a certain place or setting or 'lived in a particular context', Tudor (2001, p.135). While teaching language, we must not overlook the culture i.e. socio-political and geopolitical aspect, institutional aspect of a country where we teach. Byram and Grundy (2003, p.1) acknowledge that language teaching profession has given 'recognition of the social and political significance of language teaching.' Context is the very first thing to be taken into account before any methodological or language system decisions are taken, according to Bax (2003, p.284). Nor do we need to assume (despite Probhu 1990) that 'each context will necessitate a directly derivable method of its own - an eclectic approach may well be the best way to deal with a varied classroom', Bax (2003, 
p.284).We presume that context is a vital determiner of the success and failure of learners. Bax (2003,p.284) further opines that 'Good teachers naturally take account of the context in which they teach - the culture, the students, and so on - even when they hold that CLT is essentially the answer'. Davies (1999, p.35) holds 'If we look more closely at these functions of education in development, we need to recognise that ELT in the context of aid to developing countries has its own political, economic and cultural implications'.

Richards and Rodgers (2001, p.248) consider context as the 'starting point in language program design'. They underline that when teaching learning occurs the following contexts should be brought into consideration:
i. Cultural context
ii. Political context
iii. Local institutional context and
iv. Context constituted by the teachers and learners in the classroom.

Now, we will discuss the significance of the above mentioned contexts in foreign language (English) teaching and learning.

\section{Importance of cultural context}

Cultural context embodies the total set of beliefs of the people of a particular society. It also refers to attitude, behaviour, social customs, and habits of the people of a society. In fact, culture embodies the whole society. Shahidullah (1999, p.47) maintains 'socio- cultural variables are culture specific and hence they vary from one culture to another. Modes of learning, therefore, vary from culture to culture, context to context. An appropriate method is, therefore, one that matches with learners' socio- cultural variables'. Teachers have to value the cultural context whenever they intend to apply a certain approach or method. As it plays a vital role in human life, it cannot be ignored in any way. Successful language teaching demands awareness of cultural context where teaching occurs. Indeed it is important to recognise that what happens in a specific classroom is influenced by political, social, and cultural factors of the large community' (Mckay, 2003), cited in the dissertation of Islam, (2003, p.23). If cultural context is not properly counted and judged, the effort of applying any particular approach or method is destined to be a failure. For example, if someone is teaching in an Arabian country she/ he must keep in mind Arabian culture if she/he is a non-native teacher. In Holliday 
(1994,p.54), Dudley-Evans and Swales (1980) Osterloh (1986) and Parker et al. (1986) describe 'the influence of Koranic attitudes to thought and language on the way in which students from the Middle East approach reading and writing ...' Similarly western, eastern, Asian culture, etc. have their own value in their respective contexts, they find in their study. And Bower (1980a) exposes the influence of Buddaism in India, cited in the same book.

Successful language learning demands language users to know the culture that underlies in a language. It is also true that learner's cultural background impacts their ability to understand the text. Understanding the culture of the text is a requirement for successful language learning. Tseng (2002, p.12) opines 'without the appropriate cultural schema to aid understanding, what is learnt must necessarily be incomplete'. Between language and culture there exists a very deep and close binding. There is an interaction between them. They are so closely interwoven that one cannot be isolated from the other. Jiang (2000, p.328) quotes from Brown (1994, p.165), 'A language is a part of a culture and a culture is a part of a language; the two are intricately interwoven...'

In Bangladesh, I have noticed that cultural context is playing a vital role in language teaching. The Bangladeshi culture is inhibiting the successful implementation of CLT there. It was expected that there would be a revolutionary achievement in English teaching and learning after the introduction of CLT. But the euphoria is gone. Due to the cultural gap, our English teaching and learning is in alarming position. Traditionally, it is found that most of the Bangladeshi English language teachers are great admirers of the Grammar-Translation method. From our classroom observation we are convinced that our language teachers tend to translate the reading passages into Bangla instead of using L2 (English) to explain or interpret those texts. It is also factual that students expect their teachers will translate the texts, problems, etc. into Bangla. And most teachers prefer to explain or teach grammar in a didactic fashion. It is found that there is a sort of teacher resistance in the implementation of CLT. They think that their forefathers learned English through the Grammar-Translation method. The social context was in fact not in favour of it. The majority of the teachers are not familiar with this new approach (CLT). They lack proper guidelines. A lion's share of them either are not prepared or under prepared to deal with the new syllabus. They are failing to keep pace with the new approach. Without understanding its nature, they try to implement it as they are asked by the Ministry of Education. Hoque 
(1999, p.95) observes 'the traditional grammar-translation method effective in a second language situation and deeply rooted in the minds of our English teachers, began to be, and is still being, widely used'.

Cultural gaps, lack of orientation, lack of training and orthodox view of the teachers are making the situation more complex and grave. There cannot be any alternative to a trained teacher for the successful application of any approach or method. It echoes in the voice of Professor Shamsul Hoque (2002), the ELT adviser of Bangladesh Open University when he says 'with the introduction of Communicative Syllabus, the text books and assignment system at primary, secondary and higher secondary levels, most teachers are not trained in CLT would find it difficult to teach and test their students.' Even after the introduction of CLT, it is found that in most of the classrooms the traditional 'teacher centred' lecture method is still going on. In fact, teachers are the key role players and engineers in applying a new method or approach. But their beliefs, behaviour, social customs, in short, cultural contexts are contributing to the failure of CLT in Bangladesh.

\section{Importance of political context}

Sometimes the understanding of the political context is vital in language teaching. At present, the world is seeing lots of regional and international organizations in this era of globalization. Some influential organizations like EU (European Union), ASEAN (Association of South-East Asian Nations), etc. have brought the issue of the consideration of the political context in language teaching. The mobility factors, revolution in technology provide teachers and pupils with constant and immediate contacts with people of other culture and geo-political background. With emergence of EU, the European community has 'to consider more specifically the policies for mobility and education which most effect language teachers' (Byram and Risager, 1999, p.43).EU has opened the doors for its member countries to move freely. Mobility for young people at university level or vocational education and in different employment is common among EU countries, as their citizens have acquired 'European citizenship'. This sort of political context must be considered during language teaching. Otherwise, the effort of applying any approach and method will end in smoke. Byram and Risager (1999, pp.46-47) write 'In language teaching, it is the encounter with other culture, other values, concepts and behaviours, which creates a reflection on one's own culture, and the focus on engaging with others is a political 
dimension ...' Though political context is not a common issue of language teaching in every nook and corner of the world, it is becoming an important factor in teaching and learning a foreign language as there emerges more and more regional and international organizations after the ending of cold war.

If we look back to the history of Bangladesh, we will find that the political context played a significant role in English teaching and learning. With the end of British colonial rule (1947) Pakistan took 'Urdu' as its state language. But due to violent opposition from East Pakistan (today's Bangladesh) 'Urdu' and 'Bangla' had been made the state languages of Pakistan. Before 1971, English had been the lingua franca between East and West Pakistan. But after the liberation (1971), Bangla was made the state language, and the status of English was drastically reduced. Specially, in 1983 when Bengali Introduction Law was promulgated English suffered a serious setback. Rahman (1999,p.13) maintains 'Thus English lost its previous status.......the consequences began to be felt in all sectors, especially in the field of education...more and more students were coming to the university for higher studies with an inadequate command of English'. English was made optional in Bachelor's Degree Course. The result was severe and damaging. It is generally believed that the standard of English fell because of that decision. It is true that our students study English for twelve years from class one to Higher Secondary Class. If this twelve years of study cannot not give our students control over English language, two more years of studying English at Degree level would not dramatically improve their linguistic and communicative competence. However, this two years of study would definitely contribute to their language skill. That is the reason why it is felt that the standard of 'English fell to abysmal depths in public schools, colleges and universities', Fakrul, Niaz and Ahmed, (Eds), (2001,p.viii). Attempts were made to translate all the books into Bangla. At present, the English course has now come back with a vengeance, making itself obligatory for the students of all faculties. An emotional political decision was taken to establish Bangla in all spheres by eradicating English which caused an almost irrecoverable loss in English teaching in our country. Due to poor proficiency in English, students fail to achieve higher degrees from Bangladesh let alone from the developed world. We are to choose bad from the worst for running the offices of teaching, administrative and technical sectors. Moreover, our manpower exportation is largely affected. Today the nation has to pay heavily for that short-sighted political decision. 
English language teachers had to comply with the political context while they were applying any method or approach during language teaching. They could not overlook, ignore or deny top-down guidelines imposed upon them. Understanding English as a global language and realizing the importance of the ability to communicate in 'lingua franca English' all concerned in Bangladesh have realized the need for an improvement from the deteriorating teaching learning situation. Later on, when the political context changed, teachers got a new paradigm in language teaching. The realization of the political leaders has helped to introduce CLT in Bangladesh and we are optimistic that in near future language teaching and learning will highly be facilitated from this.

\section{Importance of institutional context}

The aspect of Institutional context is broader than the classroom aspect. We perceive that the nature of institutional expectations and support shapes pedagogy. Kelley and Eggington (2000,p.151) argue that ' support for teachers, the amount of the learning time ,length of teaching cycles, pay and funding are concrete factors that may facilitate or impede language teaching and learning'. There are some rules and regulations (written or unwritten) that are practiced in every institution. These rules vary from context to context i.e. the institutional context of a school will differ from that of a college or a university. An institutional context of a conservative Arabian country or even of Bangladesh will vary from a liberal country. In Bangladesh there are lots of institutions where co-education is not allowed. In Madrasha (religious school), co-education is out of the question, though there are some small number of Madrashas which allow coeducation up to junior secondary level (Class viii, age-12/13). Language teachers have to uphold respective institutional contexts when they teach there. They are not free; rather they are bound in some institutional rules and regulations. They cannot apply every technique from their repertoire while they teach. They are to interfere 'with a powerful existing milieu' (Holiday, 1994, p.65) of the particular institution. While applying a method or approach, teachers have to compromise with the existing institutional context. There are some institutions in Bangladesh where interaction between male and female students is seen as blasphemous. A language teacher cannot arrange any group work, pair work, dialogue practice, etc. in those institutions. Even there are restrictions on teachers' activities. Male teachers cannot talk or mix with the female students freely. They have to be very cautious and careful while they deliver lectures or talk with female students. Teachers are obliged to abide by the norms and 
practices of those institutions. They have to apply different sorts of techniques while teaching a foreign language (English).

While I was teaching in a Madrasha (Darul Ulum Alia Madrasha, Chittagong, Bangladesh) I had to comply with that institution's context. When I was teaching in a college (Cantonment Public School and College, Chittagong), I would have to abide by the rules of the institute i.e. checking home work, ensuring the teaching of a particular lesson, checking the school diary, giving weekly/monthly tests, etc. But the university (International Islamic University Chittagong, Bangladesh) where I am working now has a different context. I am to shoulder here different types of responsibilities- academic and administrative. We are to give an English Placement Test before allowing the students to study in honours courses. Considering the students' age and IQ level, class size, course load, course types, I am to adopt different strategies while I am to apply an approach or method to teaching foreign language i.e. English. Like me, all teachers have to abide by the institutional context where they carry out language teaching in order to make an approach or method effective while they apply it.

\section{Importance of classroom context}

The context constituted by teachers and learners in the classroom is one of the significant features which should be considered with much attention during implementing any approach or method. Classroom behaviour must properly be understood. 'We have to see classrooms as sites where identities are produced and changed. We need to understand that these identities are multiple and shifting and tied to language and language learning'(Kelley and Eggington,2000,p.99). Curriculum developers or teachers should have clear idea about the classroom context, otherwise it will 'seriously inhibit learning' (Holliday, 1994, p.35).If any new approach or method is to be applied, teachers must ensure 'the classroom culture is sufficiently hospitable and resilient to endure the trauma of change' (Holliday, 1994, p.46). During language teaching, especially a foreign language, a teacher has to tackle a very complex situation. She/he has to adjust students to new situations. Her /his sole responsibility is to make lessons enjoyable and entertaining in order to make sure (English) language teaching a successful one. She/he has to manage everything very efficiently so that students feel interested in the lesson. She/he is just like both 'an actor' and 'stage manager' in a theatre. She/he is to follow and lead students to follow a lesson and cope with the new situation. Gil (2002,p.278) maintains 'in the foreign language classroom, the teacher 
at the same time an actor and stage- manager, who has to follow and lead students to follow a script and cope with the new situations that emerge so as to make the right decisions for FL classroom play to go on smoothly and fluently'.

In fact, teachers should not be rigid in the classroom teaching when they apply any method or approach. Factors like logistical, cultural and institutional forces at play will influence a teacher during teaching. Teachers have to pick and choose methods according to the contextual needs of the classroom. Certainly, they do not have to choose classroom techniques from the existing packaged methods. They may adopt techniques that have worked for them in their instructional experience. Canagarajah (2000,p.140) also acknowledges ' it has been pointed out that classroom realities rarely correspond to any recognizable methods (at least as they are packaged by the research and publishing industry). Even when teachers start with a specific method in mind, they are influenced by classroom contingencies to introduce radical changes as they teach'. Investigation of classroom culture exposes different critical factors. Those factors will obviously help to take decision in syllabus or methodology change. So, language teachers should keep this matter in their mind while they apply any new approach or method. I have also observed similar sort of opinion in Kumaravadivelu (1994) cited in Canagarajah (2000, p.140), when he states '...Teachers are compelled to give up thinking in terms of predefined/pre-packaged methods and creatively devise pedagogical strategies from the bottom upwards to suit their specific classroom conditions'. In his teaching project with the Tamil - Lankan students, Canagarajah (1993) observes his students started to resist his more Westernised teaching approach and opted instead for an approach to learning with which they were more familiar.

In Bangladesh, while we teach English, we cannot stick fully with CLT. The classroom realities compel us to adopt different techniques. There most of the students are not at all familiar with the English culture. Moreover, outside the classroom, they hardly find anyone to help them to understand any English lesson. Conversation in English is almost rare, let alone outside the classroom but not even inside the classroom during English language class. So, these crucial factors force language teachers to adopt their own strategies while they apply any approach or method. Otherwise, the main purpose i.e.-the teaching of this language will never be satisfactorily achieved. That is the reason why Richards and Rodgers (2001, p.248) believe 'In trying to 
apply approaches or methods, teachers sometimes ignore what is the starting point in language program design, namely, a careful consideration of the context in which teaching and learning occur, including the cultural context, the political context, the local institutional context, and the context constituted by the teachers and learners in their classrooms'. In fact, in no way we can disregard contextual realities.

\section{Conclusion}

The ability to learn a foreign language is a natural human characteristic, but it is an undeniable fact that contextual factors immensely influence that capacity. We understand that learners in different contexts have different learning experiences and different ways of teaching and learning. Many aspects of the context such as cultural context, political context, institutional context, classroom context, etc. are clearly as important as teaching methods or approaches. A heightened awareness of contextual factors is imperative in order to make foreign language (English) teaching effective. Shahidullah (1999,p.49) reiterates 'Experience of learning, and modes of teaching and learning being different from context to context, teaching - learning methods originating in one culture clashes with, does not work well in other contexts'. Hence English teachers cannot but consider this crucial issue of context. We also agree with Bax (2003, p.286) that 'good teachers everywhere pay attention to context; good training courses pay attention to context'.

\section{Bibliographies}

Anthony, E. M. (1963). Approach, method and technique. English Language Teaching, 17(2)

Bax, S. (2003). The end of CLT: a context approach to language teaching. ELT J, 57(3). Oxford University Press.

Byram,M. and Grundy,P.(2003). Context and Culture in Language Teaching and Learning. Multilingual Matters Ltd.

Byram, M. and Risager, K.(1999). Language Teachers, Politics and Cultures. Multilingual Matters Ltd.

Canagarajah, A. S. (2002). Globalization, Methods, and practice in periphery classroom Globalization and Language teaching (Eds) D. Block and D. Cameron. Routledge.

Canagarajah, A. S. (1993). Critical ethnography of a Sri Lankan classroom: Ambiguities in student opposition to reproduction through ESOL. TESOL Quarterly, 27(4), 601-626.

Davies, P. \& Pearse, E.(2000). Success in English Teaching. Oxford University Press. 
Davies, P. (1999) .ELT, literacy and social development - a critical review of the relative status of ELT in the context of educational development. International Conference on : National and Regional Issues in English Language Teaching : International Perspective, Organized by ELTIP, Bangladesh.

Fakrul, A., Niaz, Z. \& Ahmed, T. (Eds) (2001). Revisioning English in Bangladesh. (Eds). The University Press Ltd.

Gadsby, A. (ed.) (1995). Longman Dictionary of Contemporary English. $3^{\text {rd }}$ (Eds). Longman Group Ltd.

Gil, G. (2002). Two complementary modes of foreign language classroom interaction. ELTJ 56(3). Oxford University Press.

Hall, J. K. \& Eggington, W. G. (eds.) (2000). The Sociopolitics of English Language Teaching. British Library Cataloguing in Publication Data. Great Britain.

Holiday, A.(1994) . Appropriate Methodology and Social Context. Cambridge University Press.

Hoque, S. (2002). English as a Second Language: A Priority Progamme, The Daily Star January27, 2002

Hoque, S. (1999). ELT issues in Bangladesh: An Overview, International Conference on: National and Regional Issues in English Language Teaching: International Perspective, Organised by ELTIP, Bangladesh.

Hornby, A. S (1996). Oxford Advanced Learner's Dictionary. $5^{\text {th }}$ Edition. Oxford University Press.

Islam, Z. (2003). Bridging the Gap: Curricular Innovation and Teacher Preparation Perspective in Bangladesh. Dissertation done in the University of Essex.

Jiang, W. (2000). The relationship between culture and language. ELTJ, 54(4). Oxford University Press.

Johnson, K. \& Johnson, H.(eds.) (1998). Encyclopedic Dictionary of Applied Linguistics. Blackwell Publishers Ltd. Oxford, UK.

Kumaravadivela (2002). Globalization, Methods, and practice in periphery classroom Globalization and Language teaching (Eds) D. Block and D. Cameron. Routledge.

Larsen Freeman, D. (2000). Techniques and Principles in Language Teaching. Oxford University Press.

Probhu, N. (1990). There is no best method- Why? TESOL Quarterly, 24(2), 161-76.

Rahman, H. M. (1999). English Language Teaching in Bangladesh: didactics on the pragmatics of a language teaching policy, International Conference on: National and Regional Issues in English Language Teaching: International Perspective, Organised by ELTIP, Bangladesh.

Richards, J. C. and Rodgers, T. S. (2001). Approaches and Methods in Language Teaching. Cambridge University Press

Shahidullah, M. (1999). Towards an Appropriate Methodology for ELT in Bangladesh, International Conference on: National and Regional Issues in English Language Teaching: International Perspective, Organised by ELTIP, Bangladesh.

Tseng, Y. H. (2002). A lesson in culture. ELTJ, 56(1).OUP

Tudor, I. (2001). The Dynamic of Language Teaching. Cambridge University Press. 